\title{
A Review of Differential Attainment in Recruitment in the UK Medical Profession
}

\section{ABSTRACT}

Differential attainment is the phenomenon where groups of people, in this case members of the medical profession, experience differences in their achievement based on factors which are beyond their control. There are multiple contributory factors including gender, age, race, ethnicity, socioeconomic and disability. The evidence suggests that medical professionals from Black and minority ethnic backgrounds, women, those with disability, international medical graduates, those from low socio-economic status and from geographical low participation (in higher education) areas tend to find barriers in every stage of recruitment to medical schools and later during their careers. There is emerging data over the last 5 years (post-2014) of organisations such as General Medical Council, Medical Schools Council and members of the Academy of Royal Colleges that are striving to offer transparency and annual reports which offer the opportunity for reflection and self-assessment.

The British Association of Physicians of Indian Origin has been leading a collaborative initiative with the 'Alliance for Equality in Healthcare Professions' to tackle the full range of differential attainment. This collaboration brings multiple stakeholder organisations and grassroots bodies around the table with international experts in reviewing the evidence, the data from focus groups and working to develop tangible, SMART interventions to address these disparities. This review on DA in recruitment is one of six such themes which will constitute the 'Bridging the Gap' report due in line with the Silver Jubilee celebrations of BAPIO in September 2021. The report will present evidence based, consensus on recommendations for action at national, regional and local level and areas for further collaborative research.

Keywords

Differential attainment, Bridging the Gap, BAPIO, medical profession, BME, IMG
Jyothi Srinivas, Akhila Panda, Alison Fergusan, Saman Zaman, Shevonne Matheiken, Sarthak Bahl, Umakanth, Faisal \& Veeresh Patil \& Indranil Chakravorty

Alliance for Equality in Healthcare Profession, Bapio Institute for Health Research, Bedford, UK

Jyothi.srinivas@mkuh.nhs.uk

Cite as: Srinivas, J., Panda, A., Fergusan, A., Zaman, S., Matheikin, S., Bahl, S., Umakanth, Faisal, Patil V., \& Chakravorty, I. A review of differential attainment in recruitment in the UK medical profession. Sushruta J Health Pol \& Opin Vol 14; Issue 1: 1-15 ePub 08.02.2021 DOI

https://doi.org/10.38192/14.1.12
Article Information

Submitted 28.12.2020

Revised 26.01.2021

Published 09.02.2021 


\section{Background}

Differential attainment is the gap between attainment levels of cohorts influenced by factors on which the people involved have little or no control (1). The concept has its roots in sociological research, (sometimes referred to as 'differential achievement' or 'differential educational achievement'), which challenges the system of achievement as being purely meritocratic. In medicine, differentials due to individual ability are expected, but factors such as age, gender and ethnicity have been shown to contribute to disparity in attainment (1). For the purpose of this review, we define differential attainment as a phenomenon where certain cohorts of people tend to have variable career outcomes based on factors other than capability, academic effort or motivation (2).

The UK National Health Service (NHS) is one of the most diverse workforces in the world with $22 \%$ of staff from Black and ethnic minority groups (BME) and a similarly large proportion being born or qualified overseas.(3) This diversity is most noticeable in proportions of doctors and nurses (4) and demonstrates a geographical or ruralmetropolitan skewed distribution. The reasons for such distribution is often based on governmental policy, market forces and inherent inequalities or biases that exist in the higher educational or NHS institutions. (5)(6)

The recruitment systems into UK Medical Schools and NHS organisations have been shown to disproportionately favour white applicants (7) and those from socio-economic privileged backgrounds. There is also a recognised disparity by gender, particularly in career progression, pay difference (8) and in being appointed to leadership positions. In the case of BME, born overseas, and those with other protected characteristics (as per the Equality Act 2010), the disparity is multiplied. There is sparse data on the recruitment or progression of those with disability or by sexual orientation. (5)

In this scoping review, we explore the current literature on differential attainment in medical recruitment in the UK (and NHS) in various levels including undergraduate courses, specialty training, associate speciality doctors, primary care and at Consultant level. We focus primarily on ethnicity and gender as the data on recruitment in respect to health, disability or LGBTQ+* is scarce. We examine possible reasons for these discrepancies and explore ways to address this injustice.

\section{Why is this important?}

The UK NHS was founded upon the principle that every person is treated fairly, equally and free from discrimination regardless of their 'gender, race, disability, age etc.'(9). Indeed, the acclaimed poet and activist, Maya Angelou wrote:

"We all should know that diversity makes for a rich tapestry, and we must understand that all the threads of the tapestry are equal in value no matter what their colour".

This applies to all factors that differentiate us as humans. Ultimately, this desire to offer a 'level playing field' is critical for a fair society, supportive professional excellence, sustainable and safe healthcare delivery to patients $(10,11)$. Discrimination or bias that exists in the recruitment of the medical workforce adversely affects morale, motivation, self-worth, and impacts on the performance of teams, resulting in poor organisational outcomes. Ultimately, it hurts the workforce and therefore service users/ patients (12)(13). It is vital to examine these disparities, explore the contributors and consider how they might be remedied.

\section{Methods}

A search was conducted on Google Scholar to find all the published research available. The search terms used included "differential attainment", "postgraduate training", "recruitment bias", "gender and postgraduate recruitment", "speciality training recruitment", "disability", "disabled doctors", "sexual orientation in recruitment", "LGBTQ+ doctors", "diversity", "medical school recruitment" and "medical school application". Other sources such as grey literature, opinion articles and social media were also used to gain a comprehensive picture. Publications chosen explored data from university recruitment sites (e.g. UCAS)/surveys/test results to predict attainment levels at college/medical school in relation to ethnicity and socio-economic status. Each of the studies looked at multiple demographic factors such as age, sex, ethnicity, etc. and how these influenced educational outcomes. 
Fig 1: Study Selection Flow Diagram

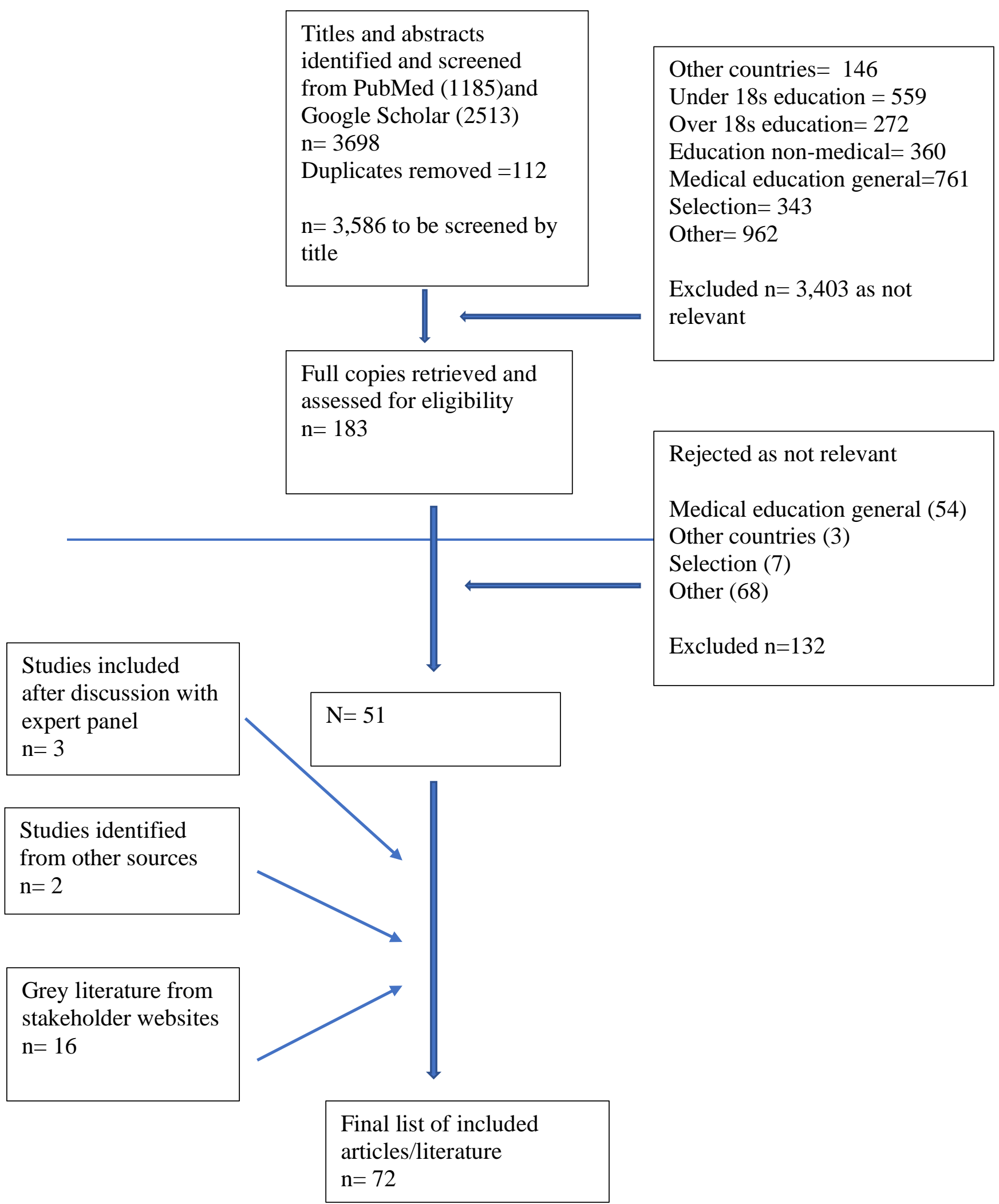


What is the scale of DA?

(1) Undergraduate recruitment

(a) Ethnicity

According to the Selecting for Excellence Report (2018), 57\% of applicants to UK Higher Education (including medicine) are White, 25\% Asian and 8\% Black (14) as seen in Figure 2. Hence there appears to be an over-representation of both Black and Asian students in applications to medical schools, when compared to the ethnic distribution from the pooled annual population survey data from 20112016 of the UK (Asian 8\%, Black 3.5\% vs 84.9\% white). (15). The highest increase in applications in the last 5 years has been in students from Black heritage $(58 \%)$. However, the success rates for entrants continues to be skewed in favour of white applicants.

Figure 2: UCAS applications by ethnicity

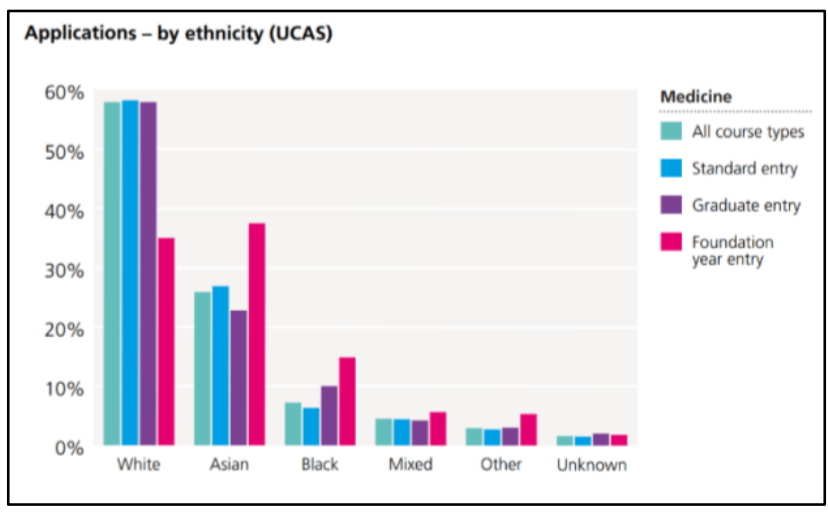

(b) Socio-economic diversity

In the past few years, programs have been implemented to increase representation from previously under-represented groups, but there has been no change for those from geographical low participation areas and those from low socioeconomic status (SES). Survey data shows that $20 \%$ of the secondary schools in the UK provide $80 \%$ of the applicants for medicine (18)(19). Furthermore, medicine appears to be lagging behind in terms of socioeconomic diversity, with $50 \%$ of applicants coming from privileged backgrounds, compared to $91 \%$ from state-funded schools, among students studying a non-medical first degree, figure 3. First degree MBBS students
Some medical schools which support the widening participation initiatives, (offering foundation courses to under-represented groups) tend to have a higher proportional intake of BME students for the 5-6 year MBBS course, but in graduate entry courses, there is a higher proportion of white (82\%) candidates who are successful. (16) There is a dichotomy of data perhaps due to discrimination at school level, as overall BME students tend to achieve lower grades at GCSE, while achievement at the highest grades is similar to that of White students. BME students are more likely to take A levels in science (particularly chemistry), but are seen to have lower A-level grades than white medical school applicants. (17) This phenomenon of underperformance in Medical school assessments continues to be recurring theme. with one or more parents that have attained a higher education qualification, account for $50 \%$ compared to $36 \%$ for other first degree applicants. (20) There is an obvious social gradient of applicants and applicants with accepted offers with 20-35\% of applicants living in the most affluent tenth of postcodes vs $2-6 \%$ in the least affluent tenth. Applicants resident in the most deprived postcodes, with parents from lower SES occupational groups, and attending non-selective state schools were much less likely to be successful in obtaining an accepted offer of a place at medical school further steepening the observed social gradient. (18) 
Figure 3: Socioeconomic backgrounds of medical students (BMA, 2015)

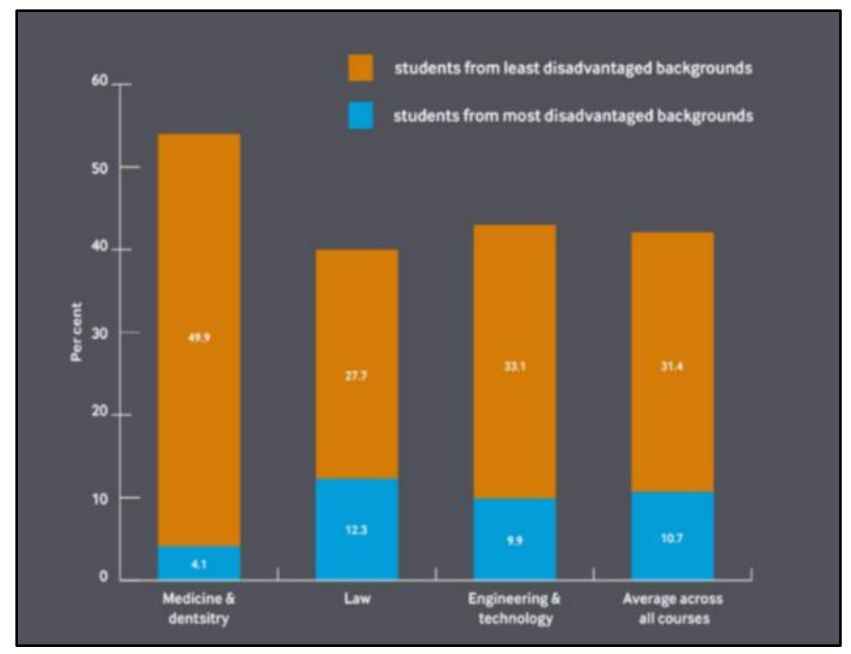

(c) Gender

The number of female medical students has grown considerably over time, and they now make up more than half of all medical students and contributing to the rise in female doctors, as they qualify and move into postgraduate training and employment. The Kings Fund estimated that in 2011, 43 per cent of all doctors in England were female, with numbers increasing at a faster rate than male doctors, accelerating demand for flexible working, and raising the prospect that more doctors may be required to provide care in future years, figure 4 . (21) However, the latest independent report highlights the gender pay disparity which reflects a complex myriad of issues relating to career choices, career breaks and barriers to applying for senior/ responsible positions. (8)

Figure 4: Gender proportionality for medical school entrants 1980-2010

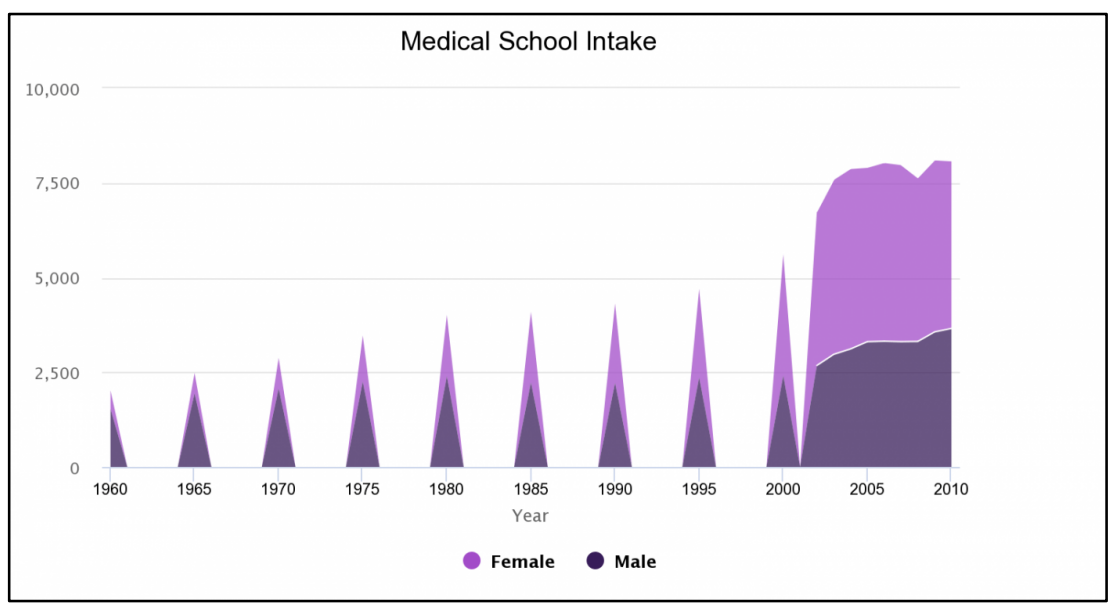

(d) Disability \& Protected Characteristics

For UK employment purposes, disability is defined as a physical or mental impairment which has a substantial and long-term adverse effect on a person's ability to carry out normal day-to-day activities. It covers physical disability, some medical conditions and mental illness. Disability discrimination has been illegal in the UK since 1995, with the law now incorporated into the Equality Act 2010.(22) In all higher education providers, the overall number of students with a known disability is increasing year on year (14\% in 2018/19), due primarily to students identified as having a mental health conditions. Of students with a known disability in 2018/19 the category of specific learning difficulty is the largest group accounting for $36 \%$ of the total including a specific learning difficulty such as dyslexia, dyspraxia or Attention Deficit Hyperactivity Disorder, and, a mental health condition, such as depression, schizophrenia or anxiety 
disorder.(20) There has been a 33\% increase in medical school entrants declaring a disability but the overall numbers continue to be low.

\section{(2) Postgraduate recruitment}

(a) Post graduate medical recruitment in UK includes the first point of recruitment into Foundation training, and then the entry into Specialty or GP training. Specialty training comprises of two further recruitment points for specialities that do not offer a 'run-through' scheme. The data from Foundation year 2 application and appointability (2015-2019) shows that; although BME candidates are more likely to make an application (UK BME 86\% vs UK white 57\%), and are shortlisted but are less likely to be considered appointable (UK White 94\%, UK BME 92\%, European Economic Area (EEA) White 88\%, EEA BME 78\% and International Medical Graduates (IMG) BME 79\%). (23)

(b) Gender - Women are more likely to be considered appointable (94\%) compared to male applicants (90\%) at FY2 level for specialty posts.

(c) SES - 94\% were considered appointable from least deprivation index vs $92 \%$ from the most deprived.

(d) Primary Medical Qualification - Candidates with an international PMQ were less likely to be considered appointable (79\%) vs those with UK PMQ (93\%).

(e) Candidates who were working in full time capacity were more likely to be found appointable $(92 \%)$ vs those working in a flexible or less than full time capacity (90\%).

(f) There is no data on other protected characteristics

\section{(3) Speciality or Associate Specialists (SAS) and} Locally Employed Doctors (LeD)

It is important to mention the 'forgotten tribe' of doctors who choose to follow a route which was outside the formal training pathways, designated as LeDs or sometimes in SAS roles. SAS and LeD doctors in 2019 accounted for one sixth of the medical workforce in the UK, ethnically diverse and $60-70 \%$ who gained their PMQ outside of the UK (58\% BME vs 35\% white in comparison to $34 \%$ of UK licensed doctors are BME, and 53.2\% are white).(24) Hence, this data suggests that this non-training pathway maybe a last option for many disadvantaged doctors who face barriers or are unsuccessful in securing a 'training post' in their chosen specialty.

It is not surprising therefore, based on GMC published data on differential recruitment rates for disadvantaged groups, that these grades will have a preponderance of doctors from BME or IMG backgrounds. (25) A survey by NHS Employers from 64 organisations in 2019 on SAS doctors $(26,27)$ found that; career progression, pay and career development as the most common reasons for SAS doctors leaving their post. Almost 54 per cent of organisations stated that a lack of recognition of the role and contribution of LeD and SAS doctors was affecting morale and motivation.

For some doctors, achieving equivalent training to be recognised on the Medical Specialist Register may be career development in itself, as a way of gaining recognition for their skills, rather than it solely being a path to a consultant post. Survey data shows that over one fifth of SAS doctors have applied for, or are in the process of applying for equivalent certificate of training (CCT), and a similar proportion indicated they plan to apply in the future, also that nearly a third of LeDs had plans to apply for CCT. (24) Several respondents in a survey of SAS doctors in psychiatry reported that they were not eligible or opportunity including support from their employers to sit the college (MRCPsych) examination considered essential for progression. This highlighted the potential problem of people becoming stuck in non-training positions without the prospect of career progression. (28)

\section{(4) General Practitioners}

There are approximately 28000 GPs currently working in UK and data indicates that some with very low morale are particularly likely to quit patient care or to take a career break.(29) Medical students are put off careers in general practice by low perceived value of community-based working and low status of general practice (linked to a prevailing medical school culture); observing the pressures under which GPs work; and lack of exposure to academic role models or primary carebased research opportunities.(30) The current GP trainee selection process in the UK involves three stages, an eligibility check (Stage 1), the Multispecialty Recruitment Assessment, which comprises computer-based assessments of Clinical Problem Solving and Professional Dilemmas (Stage 2) and, for those achieving set cut scores on these assessments, a Selection Centre with three face-toface simulations and a written assessment, during which applicants' competency on various attributes is compared to that considered to be required for training (Stage 3) 
There is data from a comprehensive assessment in 2012, showing that BME and IMG applicants perform poorly in GP selection and subsequently in the clinical assessment tests for the MRCGP examination.(31) Although there appears to be a correlation with place of primary medical qualification, gender, and performance in knowledge tests, there is evidence of the inherent discrimination and bias faced by many aspirants from BME backgrounds. The DA in RCGP examinations and differential/ unreliable treatment by regulatory agencies (Care Quality Commission $(32,33)$ \& the GMC $(34,35))$ appears to lead to further reduction in GP numbers and continue to skew the distribution between practices in rural affluent areas versus post-industrial wastelands or inner city areas with multiple deprivation. Ultimately, this leads to a further decline in morale, professional self-worth and retention. (36) There is little regular data transparency on ongoing differential recruitment based on protected characteristics and the universal access to recruitment to GP jobs based on geographical locations.

\section{(v) Hospital Consultants}

The data from the NHS Workforce statistics (37) shows that BME doctors form a significantly fewer proportion of the consultant group (31\% vs 62\%) based on population adjusted ratios. They form a much larger proportion of the Associate Specialist and Staff Grade posts. A differential career progression exists for consultants depending on their ethnicity. When consultants apply for a senior manager position, a White candidate has a 6 times higher likelihood of success compared with a BME candidate (7). White doctors are the most likely to be in the highest paid positions: $46.0 \%$ of white doctors were consultants, whereas only $33 \%$ of Chinese or $31 \%$ Black doctors. Additionally, men were more likely to be employed in higher pay bands than women, and this gender disparity was apparent across race-ethnic groups.(38)

\section{Contributors to DA}

Although the problem of the underperformance of ethnic minorities in medical education has been much discussed, the underperformance is not unique to medical studies, as shown by analysis of HESA (Higher Education Statistics Authority) data for graduates of UK degree-giving bodies. The trend is greater in older students, in women, in part-time students, and in some subjects and at some institutions than others. It is only partly explained by variations in the students' qualifications on entry into higher education. There is very little psychometric or academic explanation for this, therefore suggesting a systemic bias.

\section{Barriers pre-university}

- Possible mismatch between academic ability and aspiration

Minority ethnic people are more likely to take HE qualifications than White people. The higher education initial participation rate (HEIPR) for minority ethnic groups in aggregate is considerably higher than the average, and they represent a higher proportion of the graduate output compared to their share of the working population. A range of factors affect $\mathrm{HE}$ entry, but aspirations and expectations of the value of, and benefits from, higher qualifications is a more significant positive 'driver' for minority ethnic than for White students, especially most Asian groups. This combines with greater parental and family influence to play a more significant role in encouraging HE participation among minority ethnic than White young people, and also in choices of what and where to study in HE. (39)

- Differential experience of academic life Minority ethnic students do not appear to participate in higher education in a uniform way. The individual minority ethnic group participation rates vary considerably overall, and their representation varies between universities, subjects, geographic regions, and courses. The minority ethnic undergraduate student body is highly heterogeneous with different personal profiles (in terms of gender balance, average age at entry, highest entry qualification, socio-economic class profile and other personal characteristics).

- Impact on Degree Performance and Employment

Though their HE initial participation rates are higher, all minority ethnic groups do not do as well in degree performance as White students on average. Even when background and other variables known to affect class of degree are taken account of, they still do less well overall. Significantly, they also do less well in the labour market, initially at least, than White graduates. They face more problems securing their preferred choice of jobs or careers. In nonmedical higher study, BME students are more likely to go on from degrees to further study or training. All minority ethnic groups have higher initial unemployment 
levels than White graduates. Minority ethnic graduates continue to be underrepresented in the graduate intakes of many large organisation(40)

\section{Gender Stereotypes}

There was also no significant gender difference in attainment at shortlisting, or after interviews, for 2016-2019 (10). However, there were differences in patterns in gender proportionality between specialties; with some specialties having disproportionate numbers of one gender. The differential attainment figures could not be calculated for specialties as there is no published gender data on applications to individual specialties. Anecdotally there are stereotypes of variable work-life balance, personality types and opportunities for flexible training which tend to determine differential proportions by gender in areas within medicine (GP, Paediatrics, Obstetrics, Dermatology have higher representation from women compared to surgery, cardiology and emergency medicine)(41,42). Gender order where women are less valued in the profession is also rife in the medical profession and is a determinant in career choices as well as attainment.

\section{Racism}

People from BME backgrounds have historically experienced more barriers in entering medicine.(43)(44). There are well described challenges in school, assessments, examinations and recruitment which are disproportionately higher. Although there is a recognised complexity of interactions of multiple socio-economic factors which lead to this disparity, inherent racism in society, also reflected in the medical profession is an important determinant. This is manifest in conscious and unconscious bias, in absence of role models, in social exclusion, othering and lack of accountability of organisational leadership. The system is sustained by the reluctance of students or doctors to complain and the widely held view within the profession that problems encountered by candidates from an ethnic minority are due to valid reasons such as 'not understanding English culture'.(4550) This issue is further compounded in doctors with an international PMQ.
There is evidence that younger applicants are more likely to succeed in recruitment to medical school and training positions than older applicants.

\section{Sexual preference}

Not much research was found on disability or LGBTQ factors. An American study (51)(52) found that $17 \%$ of surveyed physicians were found to be homophobic and others have described fear of or actual experiences of gay and lesbian doctors being refused employment due to their sexual orientation $(53,54)$.

\section{Disability}

Smith et al. (55) describe the experiences of disabled doctors highlighting various difficulties from bullying, discrimination, lack of support from employer, poor communication between occupational health and employer, as well as cumulative adverse impact on well-being. A survey conducted by the BMA acknowledged the absence of a disability inclusive culture. People reported lack of role models, facing trouble disclosing their disability and disability-related bullying and harassment. This was more pronounced in primary care. (56)

\section{Mentorship/Sponsorship}

Many students and doctors especially from BME or IMG backgrounds tend to suffer consequences of lack of equal access to resources such as coaching for medical school entrance examinations and support for interviews (57). The absence of BME doctors in senior positions tends to offer little opportunity to be inspired or be mentored to successful career pathways.

Socio-economic challenges -Multiple deprivation Potential applicants from lower SECs encounter problems with lack of parental support, poorly performing schools, career counselling, role models, opportunity to expand their knowledge / skills, leadership, self-confidence leading to lack of aspiration and therefore success. The Medical Student Councils report recommended that a widening participation program would be part of the solution to increase diversity. (57).

\section{Curriculum and Diversity}

The Windrush scandal highlighted systemic inequalities within UK organisational systems and pointed to the 
persistence of colonial influences within society. Medicine and medical education could, on some levels, be accused of "colonising" students, patients, and doctors. This poses a significant disadvantage to doctors from ethnic backgrounds who may not be familiar with the cultural and colour norms of disease presentations, colloquial descriptions of common conditions and specially face challenges in communicating difficult diagnoses or in negotiating solutions. (58)

\section{DISCUSSION}

Differential attainment is present in all walks of life and is a reflection of an unfair society. Taking most important of the factors contributing to DA, namely ethnicity and gender, the likelihood for a white doctor to be appointed to a post in the NHS has only changed from 1.57 to 1.46 between 2016 and 2019 . The impact of such differential in recruitment of medical professionals is profound and leads to discontentment, demoralisation, demotivation and ultimately results in poor patient/ societal outcomes. The causes are multifactorial and largely at systemic level. Unless all these issues are addressed, disadvantaged groups will continue to be held back from reaching their potential and systemic inequalities will persist.

Based on our review, there is still a significant DA in the recruitment of medical professionals, which poses a persistent disadvantage to black and minority ethnic groups, as well as others based on protected characteristics. This is illegal in the UK on the principles enshrined in the Equality Act of 2010. There seems to be marginally better understanding of the issues, improved transparency of data from regulators, WRES and some intervention from organisations, but these were found to be few and often ineffective. There are significant systematic policy changes that are required as well as consolidation of the effective local and regional initiatives to provide equality and justice to medical professionals.

\section{SOLUTIONS}

\section{How can diversity in medical recruitment be improved?}

The literature on reform of recruitment practice in the UK is relatively with respect to the medical profession. Identifying a gap that we hope this paper and the subsequent workshop on differential attainment may help to address. However, the literature is richer in nursing recruitment, and widening diversity in medical training outside of the
UK, which may be adopted in the UK. There is also limited evidence demonstrating a sustainable impact of interventions in improving equality and diversity in recruitment practices (59). Indeed, diverse recruitment needs to occur at every stage of the medical career in order to achieve a balanced future workforce (59). Herein, we will explore the national, organisational and individual level solutions that should be considered to improving diverse medical recruitment. Ultimately, we propose that diversity in recruitment is not achievable through isolated initiatives, but instead a systemic culture shift to truly valuing equality, diversity and inclusivity in the workforce as well as ensuring that behaviours at all levels are congruent with this for a concerted change.

\section{Macro level}

\section{1) National leadership commitment}

One of the most widely cited levers for change, is the importance of a leadership commitment to enhancing diversity. This needs to be at a national level, including government support for a diverse workforce in all sectors, including bench marking in the public sector (NHS is one of the largest employers in the world with over 1.4 million employees in 2020) and from the organisations influencing UK higher education recruitment (such as the Medical Schools Council, UK Higher Education Agency, Academy of Medical Royal Colleges, NHS Employers, Committee of University Chairs, the Higher Education Policy Institute and Universities UK). This also applies to national priorities for NHS workforce recruitment, and support by bodies such as Health Education England.

The NHS Long Term Plan (60) includes international recruitment and recognises the need for 'central support' in developing a workforce implementation plan. One of these is the national arrangement to support NHS organisations in recruiting overseas, and includes expansion of the Medical Training Initiative to allow for 'workexperience' in the NHS. These are steps in the right direction, but the workforce implementation plan needs a wider range of approaches, and central support for up-scaling, as well as being able to be highly adaptive to both local and national needs. Moreover, retention and recruitment of the workforce depends largely on how the system is deemed fair, responsive and supportive to the diverse workforce. The NHS Interim People's plan (61) sets out the principles of such support and the NHS People Promise accepts that 'our people' are best placed to say when progress has been made. From 2021 the annual NHS Staff Survey will be redesigned to align with Our People Promise (62). Using the Staff Survey as the principal way to 
measure progress will enable teams and departments, as well as whole organisations, to see their progress and take action to improve. This is a bold first step but stops short of setting benchmarks, and holding the organisations and the system to account for failure to progress. There are no stages to reach and timelines described. There is little 'teeth' therefore for such lofty aspirations.

\section{2) Legislation}

At its highest level this includes national legislation, and policies that address overall health equity concerns. Travers et al. have shown that the introduction of state legislation on workforce diversity in nursing led to significantly improved minority representation 3 years later, when compared to neighbouring American states without the same legislation. (63) This focussed on four main areas: funding, reimbursement, workforce enrichment programs and encouragement. These results support the adoption of similar policies to aid UK medical recruitment, however the lack of literature evaluating impact of these activities remains a barrier. This indicates the need for commissioning of evaluation reports on recruitment practice and differential attainment in order to encourage policy-makers. Other positive changes to the law have included those to immigration rules in 2018, which now exempt doctors from the immigration cap. This has facilitated more responsive routes for staff recruitment (60) however the government will now need to ensure that post-Brexit migration systems will support employers to recruit international staff fairly and support their progression.

\section{3) Funding}

Appropriate funding and resources must be allocated to achieve the mandate of diverse recruitment. This should include funding national recruitment support schemes. Fuller and Bridgman, describe local Health Authority funded traineeships for successfully improving diverse dental nursing recruitment(64), which can indeed be applied at a national level for similar internship roles for overseas-trained doctors, that offer on-the-job training in the NHS, beyond the purely servicing poorly supervised, geographically isolated, nontraining roles most IMGs initially occupy. At the higher education level, there needs to be targeted funding support for ethnic minority students that come from low-income groups, and those with disability in order to encourage applicants(65).

\section{4) Regulatory Bodies}

The registration process for appropriately trained oversees professionals to work in the NHS needs to be efficient, as well as safe. For example, the Nursing and Midwifery Council updated its English
Language testing requirements in 2019 to order to ensure that the competency and registration processes are proportionate and responsive to the current need. We recommend similar review by the GMC of equivalent English language assessments, and support to help pass these. We also recommend review of national professional membership examinations, which are a requirement for recruitment to higher training and consultant roles. For example, it is suggested that changes made to the MRCGP examinations led to unintended institutional racism due to over-reliance on English language skills, leading to a high failure rate among ethnic minority groups (66).

\section{5) Responsibility and accountability}

Commitment to creating a diverse NHS workforce needs to be truly everyone's responsibility, and this needs to extend across supporting national bodies, as well as down to regional and local organisations. A piecemeal approach results in an ineffective, siloed approach (67). Married with this, is the extension of accountability in order to encourage intentional support (68).

\section{6) Data measurement and dissemination}

It is important that national (and organisations) NHS recruitment strategies are accompanied by target setting and continuous measurement of outcomes to critically evaluate progress and hold accountability. Frusti et al. suggest a 'Diversity Competency Model' which includes analysis of both quantitative and qualitative data to identify trends and assess recruitment and retention practice (69). Sharing of this data is important in shaping effective recruitment strategies, and may also serve as an incentive to diverse recruitment. Greary et al. showed how sharing postgraduate medical (residency) diversity recruitment data with training program directors led to significant annual improvements in applicant and selection diversity(70). National dissemination of HEE recruitment data and individual Trust recruitment data, can also allow for benchmarking (68) and identification of specialities and organisations most in need of peer review and reform.

\section{7) National cultural and language education}

Jalal et. al. makes the case for a standard national induction programme to support oversees doctors joining the workforce to develop the cultural and professional competencies and behaviours required for further recruitment. (71) Successful diverse recruitment policies in the USA also include cultural competency education(72). Other initiatives may be dedicated cultural and language support through seminars and networking opportunities at a 
national and organisational level (73), and free language classes to support NHS employees. (74)

\section{Meso level - organisational practices}

1) Comprehensive, multifaceted and strategic diversity recruitment plans

These are preferred over plans that offer short-term purely economic incentives such as relying solely on scholarships in undergraduate medical training, as they create an environment that diversity can be purchased (68).

Deas et al. show that by adopting South Carolina's multifaceted, strategic diversity plan, a university hospital was successfully able to recruit and retain more minority group medical students, postgraduate doctors, and faculty members over 10 years(67). Weech-Maldanado et al. also support a strategic human resource management approach(75), but these must be a core organisational goal and not solely a human resources effort(76).

\section{2) Explicit board vision and mission} towards a diverse workforce

This is a pivotal factor to being able to successfully shape organisational expectations surrounding recruitment and foster a culture of inclusivity. It also conveys this as a priority message to applicants and the wider community, thus attracting minority group applicants and widening the recruitment pool(68). A key requirement is also the recruitment of organisational leaders who espouse these values(77).

\section{3) Virtuous cycles}

It has been shown that hospitals with more diverse leadership are significantly more likely to actively recruit employees from diverse backgrounds (74). Therefore, organisations should look inwardly as well as outwardly, to ensure those influencing recruitment reflect a diverse workforce(78). Diversifying leadership must be a transformational process (shifting vision and adopting a new paradigm) rather than a mere change in systems and procedures(76).

\section{4) Innovative approach to recruitment}

i) Active recruitment from minority communities must be pursued(64). Traditional recruitment methods may not be effective in widening the applicant pool at undergraduate and postgraduate levels, where the recruitment is not nationally managed. The literature has shown that methods such as community media advertising, taking advantage of social media platforms, outreach programmes (such as visiting schools and local minority communities) and using the support of community leaders may be useful(79).

ii)

$\begin{array}{llr}\text { Partnering with } & \text { champion } \\ \text { organisations. Working with }\end{array}$ organisations that provide support to diverse groups has shown to significantly increase recruitment practice of ethnic minority staff (74)(80).

iii) Holistic application screening tools. Considering the overall merits of an application more widely than the narrow constraints of traditional person specification criteria can form part of an intentional strategic diversity programme (81).

iv) Blinded applications. Although this has been adopted to national postgraduate medical recruitment after bias was found against applicants with nonEnglish names (82), we recommend this for organizational level recruitment too. Similarly, some suggest that there is over-reliance on interviews rather than objective written application scoring, which may disproportionately disadvantage ethnic minority applicants. Plint et al. found that machine marking applications led to a robust and reliable process, which was perceived as fair by candidates.(83) Where this is not possible, a holistic approach to applicant assessment may help.

\section{5) Role models and champions}

These act as ambassadors to promote diverse recruitment $(67,84)$. Organisational peer-support programmes have also shown to be beneficial in promoting diverse higher level recruitment(85), however long term evaluation data on the effect on career and workforce is lacking.

\section{Micro level (individual focussed practices)}

\section{1) Mentoring}

Some studies have found mentorship to be helpful (73)(65). In particular, Deas et al. (67) found that individual mentorship by someone of the same race/ethnicity to be beneficial, but that team based peer-mentoring should encompass diversity. However, due to the individual nature of relationships and variance in these, the 
effectiveness of mentorship should not be overestimated or relied on alone (86).

\section{2) Personalised support for IMGs}

Kehoe et al. postulate that identifying individual needs and cultural experiences is essential to help overseas doctor to adopt and flourish in a new host environment, and that this support may be provided to individuals by human resource practices. (87)

Figure 5: DA in recruitment framework for solutions

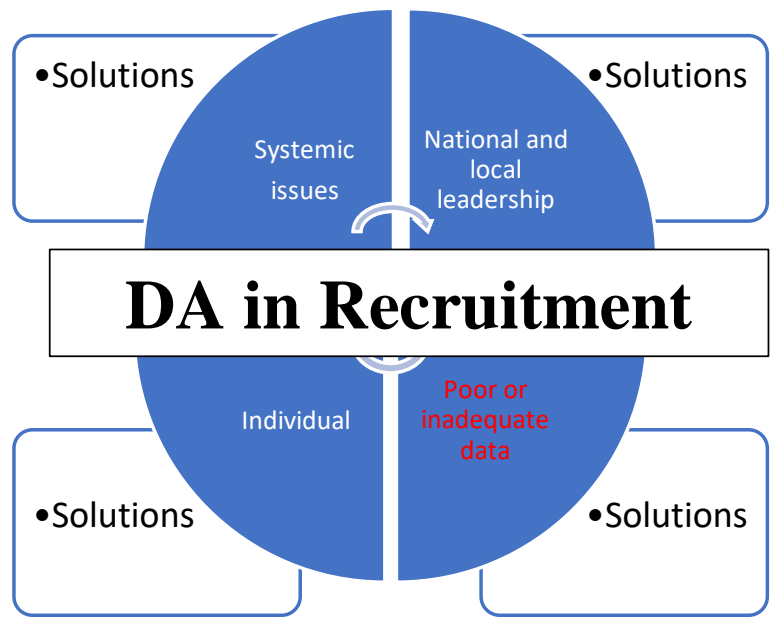

\section{Conclusion}

Differential Attainment in recruitment in an institution like NHS is a complex issue with multiple factors involved including unquantifiable issues such as unconscious bias and intersectionality. Progress would require passionate leadership in the organisations to implement evidence based interventions while also having an open mind for interventions with little or no available evidence. When data is inadequate or an intervention proves ineffective, new interventions and research should be encouraged and funded. The NHS is a large organisation and is one of the biggest employer in the UK. The NHS in itself reflects the wider society where the employees are recruited from. Some of the factors contributing to DA (and also the solutions) might be found if we look at wider racial issues that exist in our society.

\section{References}

1. General Medical Council (Great Britain). The state of medical education and practice in the UK, 2014. [Internet]. 2014 [cited 2020 Aug 1]. Available from: http://www.gmc-

uk.org/SOMEP_2014_FINAL.pdf_58751753.pdf

2. Protocol for Thematic Synthesis of Differential Attainment in the Medical Profession - 'Bridging the Gap' Series | Sushruta Journal of Health Policy \& Opinion
3) Individual applicant support

Reaching out to prospective medical students earlier in their decision making process (school level) and supporting those from underrepresented backgrounds with applications (88). This may be applied to postgraduate level recruitment as well.
[Internet]. [cited 2020 Oct 31]. Available from: https://www.sushrutajnl.net/index.php/sushruta/articl e/view/91

3. NHS workforce [Internet]. [cited 2020 Jul 8]. Available from: https://www.ethnicity-factsfigures.service.gov.uk/workforce-andbusiness/workforce-diversity/nhsworkforce/latest\#by-ethnicity-and-grade-medical-staff

4. Ethnicity-in-the-NHS-infographic.pdf [Internet]. [cited 2021 Jan 26]. Available from: https://www.nhsemployers.org//media/Employers/Documents/Plan/DIVERSITY-ANDINCLUSION/EQW19/Ethnicity-in-the-NHSinfographic.pdf

5. equality-analysis-wres-april-16.pdf [Internet]. [cited 2021 Jan 26]. Available from:

https://www.england.nhs.uk/wpcontent/uploads/2014/10/equality-analysis-wres-april16.pdf

6. Diversity within diversity: the NHS workforce from overseas [Internet]. The Nuffield Trust. 2018 [cited 2021 Jan 26]. Available from:

https://www.nuffieldtrust.org.uk/news-item/diversitywithin-diversity-the-nhs-workforce

7. Kline R. The snowy white peaks of the NHS: a survey of discrimination in governance and leadership and the potential impact on patient care in London and England [Internet]. London: Middlesex University; 2014 [cited 
2020 Oct 23]. Available from:

https://doi.org/10.22023/mdx.12640421.v1

8. New data on gender pay gap in medicine [Internet]. GOV.UK. [cited 2020 Aug 31]. Available from: https://www.gov.uk/government/news/new-data-ongender-pay-gap-in-medicine

9. The NHS Constitution for England [Internet]. GOV.UK. [cited 2020 Aug 31]. Available from:

https://www.gov.uk/government/publications/the-nhsconstitution-for-england/the-nhs-constitution-forengland

10. Progression reports [Internet]. [cited 2021 Jan 26]. Available from: https://www.gmc-

uk.org/education/reports-and-reviews/progressionreports

11. Woolf K. Fair Training Pathways for All: Understanding Experiences of Progression - Final Report. :69.

12. links-between-nhs-staff-experience-and-patientsatisfaction-1.pdf [Internet]. [cited 2021 Jan 26]. Available from: https://www.england.nhs.uk/wpcontent/uploads/2018/02/links-between-nhs-staffexperience-and-patient-satisfaction-1.pdf

13. Diversity should be a strategic priority | The King's Fund [Internet]. [cited 2021 Jan 26]. Available from: https://www.kingsfund.org.uk/blog/2018/08/diversity -should-be-strategic-priority

14. selecting-for-excellence-final-report.pdf [Internet]. [cited 2021 Jan 26]. Available from:

https://www.medschools.ac.uk/media/1203/selectingfor-excellence-final-report.pdf

15. Research report on population estimates by ethnic group and religion - Office for National Statistics [Internet]. [cited 2021 Jan 1]. Available from:

https://www.ons.gov.uk/peoplepopulationandcommuni ty/populationandmigration/populationestimates/article s/researchreportonpopulationestimatesbyethnicgroupa ndreligion/2019-12-04

16. Mathers J, Sitch A, Marsh JL, Parry J. Widening access to medical education for under-represented socioeconomic groups: population based cross sectional analysis of UK data, 2002-6. BMJ. 2011 Feb 22;342:d918.

17. McManus I, Woolf K, Dacre J. The educational background and qualifications of UK medical students from ethnic minorities. BMC Med Educ. $2008 \mathrm{Apr}$ 16;8(1):21.

18. Steven K, Dowell J, Jackson C, Guthrie B. Fair access to medicine? Retrospective analysis of UK medical schools application data 2009-2012 using three measures of socioeconomic status. BMC Med Educ. 2016 Jan $13 ; 16(1): 11$

19. Lewington K. Changes to medical education over the past 20 years. BMJ. 2012 Jun 29;344:e4246.

20. Higher Education Student Statistics: UK, 2018/19 Student numbers and characteristics | HESA [Internet]. [cited 2021 Jan 1]. Available from: https://www.hesa.ac.uk/news/16-01-2020/sb255higher-education-student-statistics/numbers
21. Medical workforce [Internet]. The King's Fund. [cited 2021 Jan 1]. Available from:

https://www.kingsfund.org.uk/projects/time-thinkdifferently/trends-workforce-medical

22. Shrewsbury D, Mogensen L, Hu W. Problematizing medical students with disabilities: A critical policy analysis. MedEdPublish [Internet]. 2018 Feb 26 [cited 2021 Jan 1];7. Available from: https://www.mededpublish.org/manuscripts/1463

23. Oracle BI Interactive Dashboards - NTS [Internet]. [cited 2021 Jan 1]. Available from: https://webcache.gmcuk.org/analyticsrep/saw.dll?Dashboard\&PortalPath $=\% 2$ fshared\%2fNTS_LTD\%2f_portal\%2fNTS\&Page=Recruit ment $\% 20$ (postgraduate)\&Done=Dashboard $\% 26$ PortalP ath $\% 3 \mathrm{~d} \% 252 \mathrm{fshared} \% 252 \mathrm{fNTS}$ LTD $\% 252 \mathrm{f}$ _portal\%252 fNTS\%26Page\%3dMain\%2520Menu\%26ViewState\%3d p8ggk68eemgg5jf1rc3m2uu28a

24. Survey of specialty and associate specialist (SAS) and locally employed (LE) doctors [Internet]. [cited 2021 Jan 1]. Available from: https://www.gmc-

uk.org/education/standards-guidance-andcurricula/projects/survey-of-specialty-and-associatespecialist-and-locally-employed-doctors

25. SAS doctors' perceptions of their role in the NHS | The BMJ [Internet]. [cited 2021 Jan 1]. Available from: https://www.bmj.com/content/344/bmj.e2819.full

26. SAS survey report published [Internet]. [cited 2021 Jan 1]. Available from:

http://www.nhsemployers.org/news/2020/07/specialt $\mathrm{y}$ and associate specialist doctor survey report published

27. Oroz C, Sands LR, Lee J. SAS doctors career progression survey 2013. Int J STD AIDS. 2016 Mar 1;27(3):231-4.

28. Claxton N, Griffin L. A forgotten tribe: a survey of the experience of working as a non-consultant career grade psychiatrist. Psychiatr Bull. 2006 Oct;30(10):369-72.

29. Fletcher E, Abel GA, Anderson R, Richards SH, Salisbury C, Dean SG, et al. Quitting patient care and career break intentions among general practitioners in South West England: findings of a census survey of general practitioners. BMJ Open. 2017 Apr 1;7(4):e015853.

30. Barber S, Brettell R, Perera-Salazar R, Greenhalgh T, Harrington R. UK medical students' attitudes towards their future careers and general practice: a crosssectional survey and qualitative analysis of an 0xford cohort. BMC Med Educ. 2018 Jul 4;18(1):160.

31. Equalities_Impact_Report.pdf [Internet]. [cited 2021 Jan 29]. Available from:

https://gprecruitment.hee.nhs.uk/Portals/8/Documents /Equality\%20Diversity/Equalities_Impact_Report.pdf

32. Allen T, Walshe K, Proudlove N, Sutton M. Using quality indicators to predict inspection ratings: cross-sectional study of general practices in England. Br J Gen Pract J R Coll Gen Pract. 2020 Jan;70(690):e55-63.

33. GP performance reviews will be part-anonymised to 'tackle bias' - [Internet]. Management In Practice. 2020 [cited 2021 Jan 2]. Available from: https://managementinpractice.com/your- 
practice/cqc/gp-performance-reviews-will-be-partanonymised-to-tackle-bias/

34. fair-to-refer-report-pdf-79011677_pdf-79021583.pdf [Internet]. [cited 2020 Oct 23]. Available from: https://www.gmc-uk.org/-/media/documents/fair-torefer-report-pdf-79011677_pdf-79021583.pdf

35. GMC more likely to investigate complaints against BME doctors [Internet]. Pulse Today. 2019 [cited 2021 Jan 2]. Available from:

https://www.pulsetoday.co.uk/news/regulation/gmcmore-likely-to-investigate-complaints-against-bmedoctors/

36. Simpson J, Waddington K. Migrant Architects of the NHS: South Asian Doctors and the Reinvention of British General Practice. Manchester University Press; 2020. $336 \mathrm{p}$.

37. NHS Workforce Statistics - September 2019 [Internet]. NHS Digital. [cited 2020 Sep 1]. Available from: https://digital.nhs.uk/data-andinformation/publications/statistical/nhs-workforcestatistics/september-2019

38. Milner A, Baker E, Jeraj S, Butt J. Race-ethnic and gender differences in representation within the English National Health Service: a quantitative analysis. BMJ Open. 2020 14;10(2):e034258.

39. Richardson JTE. The attainment of ethnic minority students in UK higher education. Stud High Educ. 2008 Feb 1;33(1):33-48.

40. Connor H, Tyers C, Modood T. Why the Difference? A Closer Look at Higher Education Minority Ethnic Students and Graduates. Res Rep. 2004 Jan 1;552

41. Alers M, van Leerdam L, Dielissen P, Lagro-Janssen A Gendered specialities during medical education: a literature review. Perspect Med Educ. 2014 Jun;3(3):163-78.

42. Pelaccia T, Delplanq H, Triby E, Bartier J-C, Leman C, Hadef H, et al. Gender Stereotypes: An Explanation to the Underrepresentation of Women in Emergency Medicine. Acad Emerg Med. 2010;17(7):775-9.

43. Woolf K, Potts HWW, McManus IC. Ethnicity and academic performance in UK trained doctors and medical students: systematic review and meta-analysis. BMJ. 2011 Mar 8;342:d901.

44. McManus IC, Elder AT, Dacre J. Investigating possible ethnicity and sex bias in clinical examiners: an analysis of data from the MRCP(UK) PACES and nPACES examinations. BMC Med Educ [Internet]. 2013 Jul 30 [cited 2020 Jul 8];13. Available from: http://dx.doi.org/10.1186/1472-6920-13-103

45. Halford S. Racism In the Medical Profession: the Experience of UK Graduates. [cited 2021 Feb 8]; Available from:

https://www.academia.edu/457985/Racism_In_the_Me dical_Profession_the_Experience_of_UK_Graduates

46. Jones L, Halford S, Leonard P. Racism in the medical profession: the experience of UK graduates. 2003.
47. Limb M. NHS doctors face racism, exclusion, and discrimination, report finds. BMJ. $2014 \mathrm{Jul}$ 31;349:g4960.

48. Mathew R. Rammya Mathew: Racism in medicinemigrant doctors aren't here just to "fill a gap". BMJ. 2020 Feb 12;368:m483.

49. Racism in the NHS: don't let the unspeakable become acceptable [Internet]. openDemocracy. [cited 2020 May 23]. Available from: https://www.opendemocracy.net/en/ournhs/racismin-nhs-don-t-let-unspeakable-become-acceptable/

50. The interacting dynamics of institutional racism in higher education: Race Ethnicity and Education: Vol 16, No 2 [Internet]. [cited 2020 Oct 23]. Available from: https://www.tandfonline.com/doi/abs/10.1080/13613 324.2011 .646255

51. Burke BP, White JC. The well-being of gay, lesbian, and bisexual physicians. West J Med. 2001 Jan;174(1):59-62.

52. Burke BP, Saunders D, White JC. Wellbeing of gay, lesbian, and bisexual doctorsCommentary: The medical profession should face up to its own homophobia. BMJ. 2001 Feb 17;322(7283):422-5.

53. Homophobia among doctors | The BMJ [Internet]. [cited 2021 Jan 29]. Available from:

https://www.bmj.com/content/308/6928/586

54. Risdon C, Cook D, Willms D. Gay and lesbian physicians in training: a qualitative study. CMAJ Can Med Assoc J. 2000 Feb 8;162(3):331-4.

55. Smith F, Goldacre MJ, Lambert TW. Working as a doctor when chronically ill or disabled: comments made by doctors responding to UK surveys. JRSM Open. 2016 Jul;7(7):2054270416649282.

56. Disability in the medical profession [Internet]. The British Medical Association is the trade union and professional body for doctors in the UK. [cited 2021 Jan 29]. Available from: https://www.bma.org.uk/adviceand-support/nhs-delivery-andworkforce/workforce/disability-in-the-medicalprofession

57. The Boar [Internet]. [cited 2021 Jan 29]. Available from https://theboar.org/2019/03/medical-schoolsdiversity/

58. Gishen F, Lokugamage A. Diversifying the medical curriculum. BMJ. 2019 Jan 23;364:1300

59. Spooner S, Pearson E, Gibson J, Checkland K. How do workplaces, working practices and colleagues affect UK doctors' career decisions? A qualitative study of junior doctors' career decision making in the UK. BMJ Open. 2017 Oct;7(10):e018462.

60. Plan NLT. NHS Long Term Plan [Internet]. NHS Long Term Plan. [cited $2021 \mathrm{Feb} 3]$. Available from: https://www.longtermplan.nhs.uk

61. NHS England » We are the NHS: People Plan for 2020/2021 - action for us all [Internet]. [cited 2020 Sep 28]. Available from:

https://www.england.nhs.uk/ournhspeople/ 
62. NHS England » Our NHS People Promise [Internet]. [cited $2021 \mathrm{Feb} 3$ ]. Available from: https://www.england.nhs.uk/ournhspeople/onlineversion/lfaop/our-nhs-people-promise/

63. Travers J, Smaldone A, Gross Cohn E. Does State Legislation Improve Nursing Workforce Diversity? Policy Polit Nurs Pract. 2015 Aug 1;16(3-4):109-16.

64. Fuller SS, Bridgman CM. A scheme to recruit Pakistani and Bangladeshi trainee dental nurses in a multiethnic area of Greater Manchester. Br Dent J. 2004 Aug;197(4):185-7.

65. Gilliss CL, Powell DL, Carter B. Recruiting and Retaining a Diverse Workforce in Nursing: From Evidence to Best Practices to Policy. Policy Polit Nurs Pract. 2010 Nov $1 ; 11(4): 294-301$.

66. Shaw Q. High failure rate of ethnic minority groups in MRCGP exam comes from changes to exam and candidate selection. BMJ. 2013 Oct 29;347:f6442.

67. Deas D, Pisano ED, Mainous AGI, Johnson NG, Singleton $\mathrm{MH}$, Gordon L, et al. Improving Diversity Through Strategic Planning: A 10-Year (2002-2012) Experience at the Medical University of South Carolina. Acad Med. 2012 Nov;87(11):1548-55.

68. Vick AD, Baugh A, Lambert J, Vanderbilt AA, Ingram E, Garcia R, et al. Levers of change: a review of contemporary interventions to enhance diversity in medical schools in the USA. Adv Med Educ Pract. 2018;9:53-61.

69. Frusti DK, Niesen KM, Campion JK. Creating a culturally competent organization: use of the diversity competency model. J Nurs Adm. 2003 Jan;33(1):31-8.

70. Geary A, Wang V, Cooper J, Roberts K, Yoo J. Analysis of Electronic Residency Application Service (ERAS) Data Can Improve House Staff Diversity. J Surg Res. 2021 Jan 1;257:246-51.

71. Jalal M, Bardhan KD, Sanders D, Illing J. INTERNATIONAL: Overseas doctors of the NHS: migration, transition, challenges and towards resolution. Future Healthc J. 2019 Feb;6(1):76-81.

72. Health Disparities: State Laws [Internet]. [cited $2021 \mathrm{Feb}$ 8]. Available from:

https://www.ncsl.org/research/health/healthdisparities-laws.aspx

73. Gardner JD. A successful Minority Retention Project. J Nurs Educ. 2005 Dec;44(12):566-8.

74. Whitman MV, Valpuesta D. Examining Human Resources Efforts to Develop a Culturally Competent Workforce. Health Care Manag. 2010 Jun;29(2):117-25.

75. Weech-Maldonado R, Dreachslin JL, Dansky KH, De Souza G, Gatto M. Racial/ethnic diversity management and cultural competency: the case of Pennsylvania hospitals. J Healthc Manag Am Coll Healthc Exec. 2002 Apr;47(2):111-24; discussion 124-126.

76. Dreaschlin J. Diversity Leadership. Chicago, IL: Health Administration Press; 1996
77. Schuster MA, Conwell WD, Connelly MT, Humphrey HJ Building Equity, Inclusion, and Diversity Into the Fabric of a New Medical School: Early Experiences of the Kaiser Permanente Bernard J. Tyson School of Medicine. Acad Med J Assoc Am Med Coll. 2020 Dec;95(12S Addressing Harmful Bias and Eliminating Discrimination in Health Professions Learning Environments):S66-70.

78. Yu PT, Parsa PV, Hassanein O, Rogers SO, Chang DC. Minorities struggle to advance in academic medicine: A 12-y review of diversity at the highest levels of America's teaching institutions. J Surg Res. 2013 Jun $15 ; 182(2): 212-8$

79. Is your hospital culturally competent? (And what does that mean exactly?) - PubMed [Internet]. [cited 2021 Feb 8]. Available from:

https://pubmed.ncbi.nlm.nih.gov/15926357/

80. Mmeje O, Price EAN, Johnson TRB, Fenner DE. Galvanizing for the future: a bottom-up departmental approach to diversity, equity, and inclusion. Am J Obstet Gynecol. 2020 Nov 1;223(5):715.e1-715.e7.

81. Spottswood SE, Spalluto LB, Washington ER, Donnelly EF, Birch AA, Bradshaw ML, et al. Design, Implementation, and Evaluation of a Diversity Program for Radiology. J Am Coll Radiol. 2019 Jul 1;16(7):983-91.

82. Aneez Esmail and Sam Everington: The perils of researching racial discrimination [Internet]. The BMJ. 2020 [cited 2020 May 23]. Available from: https://blogs.bmj.com/bmj/2020/02/13/aneez-esmailand-sam-everington-the-perils-of-researching-racialdiscrimination/

83. Plint S, Patterson F. Identifying critical success factors for designing selection processes into postgraduate specialty training: the case of UK general practice. Postgrad Med J. 2010 Jun 1;86(1016):323-7.

84. Sunago M. Strategies for Nursing Leaders on Recruiting and Retaining a Diverse Workforce. Creat Nurs. 2020 Feb 1;26(1):17-22.

85. Sokal-Gutierrez K, Ivey SL, Garcia RM, Azzam A. Evaluation of the Program in Medical Education for the Urban Underserved (PRIME-US) at the UC BerkeleyUCSF Joint Medical Program (JMP): The First 4 Years. Teach Learn Med. 2015;27(2):189-96.

86. Escallier LA, Fullerton JT. Process and outcomes evaluation of retention strategies within a nursing workforce diversity project. J Nurs Educ. 2009 Sep;48(9):488-94.

87. Kehoe A, McLachlan J, Metcalf J, Forrest S, Carter M, Illing J. Supporting international medical graduates' transition to their host-country: realist synthesis. Med Educ. 2016 Oct;50(10):1015-32.

88. Beacham T, Askew RW, William PR. Strategies to increase racial/ethnic student participation in the nursing profession. ABNF J Off J Assoc Black Nurs Fac High Educ Inc. 2009;20(3):69-72. 